\title{
Herbal medicines for urinary stone treatment. A systematic review
}

\author{
Elena Monti ${ }^{1}$, Alberto Trinchieri ${ }^{2}$, Vittorio Magri ${ }^{3}$, Anne Cleves ${ }^{4}$, Gianpaolo Perletti ${ }^{5,6}$ \\ ${ }^{1}$ Department of Biotechnology and Life Sciences, Università degli Studi dell'Insubria, Busto A., Italy; \\ 2 Urology Unit, A. Manzoni Hospital, Lecco, Italy; \\ ${ }^{3}$ Urology Secondary Care Clinic, ASST-Nord, Milano, Italy; \\ ${ }^{4}$ Cancer Research Wales Library, Cardiff University Velindre Hospital, Cardiff, UK; \\ ${ }^{5}$ Department of Basic Medical Sciences, Faculty of Medicine and Medical Sciences, Ghent University, Ghent, Belgium. \\ ${ }^{6}$ Department of Biotechnology and Life Sciences, Section of Medical and Surgical Sciences, Università degli Studi dell'Insubria, \\ Busto A., Italy.
}

\begin{abstract}
Summary Objective: To analyze the clinical evidence on the efficacy of phytotherapy in the treatment of calculi in the urinary tract.

Methods: To be eligible, full-length articles should include the results of randomized controlled trials enrolling patients affected by urolithiasis, reporting any comparison between an experimental herbal agent versus placebo or any active comparator, aimed at preventing the formation or facilitating the dissolution of calculi in any portion of the urinary tract.

Fifteen databases were searched for relevant references. The primary outcomes investigated were (i) the reduction of stone size and/or number and (ii) the urinary excretion rates of calcium, urate, or oxalate. The secondary outcome of the review was the adverse effects (AE) of treatment. Risk of bias (ROB) and quality of the evidence were assessed according to Cochrane and GRADE guidelines. We performed a randomeffect meta-analysis.
\end{abstract}

Results: 541 articles were retrieved and 16 studies were finally confirmed as eligible. Multiple Cochrane ROB tool items were rated as having high risk of bias in each analyzed trial report. Pooled analysis of continuous data could be performed for three different comparisons: (i) phytotherapy versus citrate as single agent (ii) phytotherapy versus placebo, (iii) preparation of Didymocarpus pedicellata (DP) -combined with other herbal agents- versus placebo. Results showed that citrate is superior to phytotherapy in significantly decreasing both the size of urinary stones (mean difference: phytotherapy, 0.42 $\mathrm{mm}$ higher; $95 \%$ CI: 0.23 to $0.6 ; Z=4.42, P<0.0001 ; I^{2}=$ $30 \%)$ and the urinary excretion rate of urate (mean difference: $42.32 \mathrm{mg} / 24 \mathrm{~h}$ higher, $95 \% \mathrm{CI}: 19.44$ to $65.19 ; Z=3.63, P=$ $0.0003 ; I^{2}=96 \%$ ), assessed after 3 months on-therapy.

No significant differences in the excretion rates of urinary calcium or oxalate were found. The DP preparation was superior to placebo in inducing total clearance (risk ratio: 6.19 , 95\% CI: 2.60 to $14.74 ; Z=4.12, P<0.0001 ; I^{2}=0 \%$ ) and size reduction (mean difference: DP preparation, $4.93 \mathrm{~mm}$ lower; 95\% CI: -9.18 to $-0.67 ; Z=2.27, P=0.02 ; I^{2}=99 \%$ ) of renal and ureteral stones after 3 months of therapy. No significant differences in the inter-arm variation of excretion rates of urinary calcium or urate were found as result of the pooled phytotherapy-placebo comparison.

Herbal remedies were in general devoid of side effects and in few cases citrate appeared to induce GI disturbances in a higher fraction of patients. Most reports did not provide inferential data concerning AE, and meta-analysis was not feasible. Conclusions: Citrate is more effective than phytotherapy in decreasing the size of existing calculi in the urinary tract and in decreasing the urinary excretion rate of uric acid. A preparation containing Didymocarpus pedicellata combined with other herbal agents induces stone size reduction and clearance significantly better than placebo. Mayor limitations in the applicability of these results are the low quality of the evidence and the multiple sources of bias assessed in the studies included in the present review.

KEY WORDS: Urolithiasis; Nephrolithiasis; Urinary or kidney stones; Urinary or kidney calculi; Phytotherapy; Herbal remedies; Plant extracts; Clinical trials.

Submitted 22 January 2016; Accepted 15 February 2016

\section{INTRODUCTION}

The overall incidence of stone disease in the urinary tract appears to be increasing worldwide, though such increasing trend is sometimes debated (1). The lifetime prevalence of urolithiasis has been estimated to be $13 \%$ among men and 7\% among women In Western countries, though figures are not always univocal (2). A 2010 study in asymptomatic subjects assessed a prevalence of lithiasis of the urinary tract in $7.8 \%$ of all cases, occurring more frequently in males (9.7\% vs $6.3 \%$ in females) (3). In Italy the prevalence of urolithiasis is $4.14 \%$, with men $(4.53 \%)$ slightly outnumbering women $(3.78 \%)$, and shows a positive correlation with increasing age (4). Urolithiasis is characterized by frequent recurrence, especially in the presence of untreated metabolic disorders, recurrent urinary tract infections, anatomical abnormalities or insufficient hydration.

The composition of urinary calculi depends on the specific nucleation process triggered by calculogenic seedcrystals in supersaturated urines. Stone nucleation is often pH-dependent and may occur in the presence of metabolic abnormalities like hypercalciuria, hyperoxaluria and hyperuricosuria. Calcium-containing stones, like calcium oxalate monohydrate/dihydrate and calcium phosphate (brushite, apatite) calculi, are the most common, occurring approximately in $80 \%$ of cases (5).

Magnesium ammonium phosphate calculi (struvite) occur in 10-15\% of cases, followed by uric acid (3-10\%) and cystine/xantine stones (0.5-1\%), though these fig- 
ures are markedly affected by geographic location, age, gender, ethnicity and even meteorological factors (6). In symptomatic cases, the type of intervention depends mainly on the size and location of the calculi. Procedures like extracorporeal shock wave lithotripsy (ESWL), or more invasive interventions like ureteroscopy or percutaneous nephrolithotomy are performed, depending on the size and composition of the stone, and the general condition of the patient $(7,8)$.

In asymptomatic subjects with small-sized stones, watchful waiting is a frequently recommended strategy (9). Surveillance is often associated with administration of agents aimed at preventing the formation of new calculi, or at facilitating the reduction of existing ones. Moreover, as recurrence is a major clinical issue in postsurgery patients, secondary prevention strategies are often based on increased fluid intake and diuresis, aimed at preventing supersaturation of stone components. The armamentarium for existing stone reduction or new stone prevention appears to be quite limited. The European Association of Urology 2015 urolithiasis guidelines recommend chemolysis of uric acid stones with alkalinizing agents like citrate or bicarbonate as the only treatment with documented efficacy (Grade A recommendation) (9). Citrate raises urinary $\mathrm{pH}$ and can also decrease urinary calcium excretion and bind calcium in a soluble complex, which reduces calcium salt supersaturation. Furthermore, citrate inhibits crystal formation, growth and aggregation.

A number of herbal extracts and remedies have been tested in vitro or in preclinical in vivo models to assess their activity as chemolytic agents, or as agents preventing new stone formation. A number of clinical studies have also been performed to investigate the efficacy of various herbal remedies in the primary/secondary management of urolithiasis. However, extensive adoption of herbal remedies for urolithiasis is at present hampered by uncertain results of studies not always adequately powered. Our work was aimed at systematically reviewing the existing literature in this field and, where possible, to perform meta-analysis of data.

\section{MATERIALS AND METHOdS}

This review was prepared following the PRISMA checklist wherever possible (10), within the word count limit established by the present journal. No funding was received to support the present research or the preparation of this report.

\section{Eligibility criteria - studies, participants, interventions} We included randomized controlled trials (RCT), with an open-label or single/double-blinded design, enrolling patients of both sexes, affected by active urinary stone disease (stones of any size, or post-lithotripsy stone fragments present in the urinary tract).

We included only full-text articles written in English, reporting comparisons between any experimental herbal agent (or a supplement or preparation containing, among other components, a herbal extract/derivative), combined or not with other medicines, and placebo or any active comparator (herbal or non-herbal), aimed at preventing (primary or secondary prevention) the formation or facilitating the dissolution of calculi in any portion of the urinary tract (nephrolithiasis, ureterolithiasis or cystolithiasis). We excluded from this systematic review (i) observational studies, case-control studies, non-controlled studies, dose-finding studies, studies exclusively aimed at assessing drug toxicity (e.g., phase I studies), studies on healthy volunteers; (ii) studies investigating phytotherapy agents not directly preventing or inducing the dissolution of urinary calculi (antibacterials, disinfectants, analgesics, spasmolytics, etc.), or agents facilitating the expulsion of calculi during a renal colic (e.g.: endpoint: expulsion time), or agents "protecting" the kidney parenchyma or ureters from lesions induced by calculi or surgical devices (stents), or agents prepared with fossilized plants or organisms as single therapy; (iii) studies on "aromatherapy", homeopathy, or similar "alternative medicine" procedures, or interventions performed by non-medical healers; (iv) studies not using official taxonomic or galenic terms -but rather local or unofficial jargon- for describing herbal agents.

\section{Outcomes}

The primary outcomes considered for this review were (i) the reduction of stone size and/or number (number of residual or ejected calculi, or fragments of calculi, or stone-free rates or analogous endpoints), and (ii) the urinary excretion rates of calcium, urate, or oxalate. The secondary outcome of the review was the adverse effects (AE) of treatments.

\section{Search strategy and study selection}

Published study reports and supplementary material were identified by searching 15 relevant databases and trial registry platforms, including Medline, PreMedline, Embase, Cochrane Library, Web of Science and CINAHL. No date or language restrictions were applied and all searches were assessed as up to date on December $14^{\text {th }}$, 2015. An additional PubMed search for e-publications ahead of print was also performed. Search strategies and results are available as on-line supplementary material to the present review.

\section{Quality assessment}

The risk of bias (ROB) of included studies was assessed by two independent reviewers using the Cochrane Collaboration tool (11), and was graded as high, low, or unclear.

The quality of the evidence resulting from analysis of pooled data was evaluated according to the GRADE framework (12), and reported in a summary of findings (SOF) table (Table 1).

\section{Data collection and statistical analysis}

Data extraction was performed by three independent reviewers, using identical extraction tables. To analyze dichotomous data (e.g., number of stone-free patients at specific study time points) we extracted the number of per-protocol or intent-to-treat patients and calculated risk ratios (RR). To perform pooled analyses of continuous data (e.g., average stone size), mean differences were calculated. Analyses included the calculation of $95 \%$ 
confidence intervals (CI), and Z statistics. We analyzed only available information (available case analysis), without adopting bias-prone imputation strategies for missing data. For analysis of pooled data we used a randomeffects model. Heterogeneity was assessed by calculating the $\mathrm{I}^{2}$ value. Given the small number of studies we did not employ formal methods to explore heterogeneity, to analyze sensitivity or to assess for publication bias.

Data analysis was performed using the RevMan 5.3 software.

\section{Results}

\section{Search and study selection}

A total of 541 references were retrieved from the database searches, after de-duplication. Details are featured in the supplementary material on-line. Three independent reviewers selected 25 articles, which were considered of interest to the present review on the basis of title and abstract content. Nine articles were excluded after fulltext screening and 16 study reports were finally included in the present review (13-28). Among these reports, three lacked efficacy data of interest for the present review (15, $16,21)$, and were only evaluated with respect to the risk of bias and adverse effects of treatment.

On-line Table 1 summarizes the design of the included studies, the number of randomized patients, the experimental interventions, patient dropouts and other study details.

\section{Risk of bias in included studies}

Figure 1 summarizes the ROB evaluations for the included studies. On-line Table 2 presents the complete risk of bias assessment for the present review.

Six trial reports disclosed the randomization strategy. In five cases the ROB was low, as adequate randomization techniques were adopted $(15,16,20,24,26)$. One study adopted block randomization, allowing foreknowledge of the allocation in a fraction of patients (high ROB; 21). Ten trial reports did not disclose the randomization strategy (unclear ROB; 13, 14, 17-19, 22, 23, 25, 27, 28).

Allocation concealment was deemed as appropriate in three cases (low ROB; 15, 16, 27), whereas in two cases the ROB was rated as high $(21,24)$. The ROB was unclear in the remaining studies, as concealment strategies were not provided or not easy to interpret.

Nine trials adopted an open-label design, having high risk of performance bias $(13,14,17,18,22-25,28)$. In two studies, $30 \%$ and $10 \%$ of patients could unmask the allocation by recognizing the peculiar taste of the experimental agent (high ROB, 15, 16). Six studies were double-blinded, and showed a low risk of performance bias (19-21, 26-28). In six studies assessing physicians were blinded to treatment allocation (low risk of detection bias, 15, 16, 19, 20, 22, 24).

Five more studies were rated as having high risk of attrition bias. In three cases, no explanation was given concerning incomplete efficacy data $(15,16,22)$. In the Upadhyay et al. study, no information is given about data from 8 patients that were randomized, but apparently did not complete treatment (28). In the Shekar Kumaran

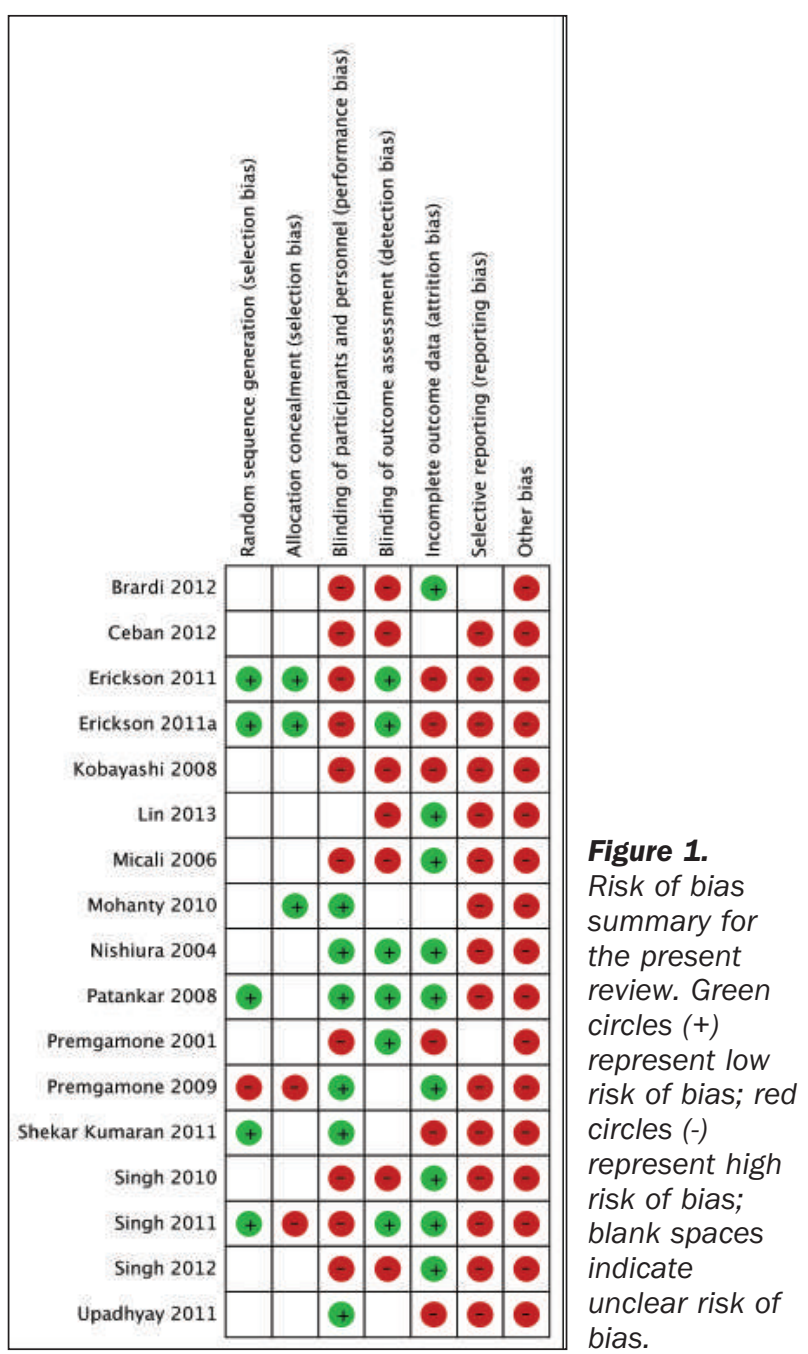

study no details were given as to whether any censoring was applied to the data pertaining to four patients who discontinued treatment in the placebo group (26).

High risk of selective reporting bias was assessed in fourteen studies (14-21, 23-28). Among these studies, eleven lacked statistical analysis and inference of key efficacy endpoints, including key comparisons between treatment arms (14-16, 19, 21, 23-28).

All sixteen studies were characterized by a high $\mathrm{ROB}$ linked to the study design, or to baseline imbalances in the clinical presentation of patients, or to the lack of adequate sample size and study power analyses. The detailed rationale for these evaluations is listed in the ROB Table (on-line Table 2) featured in the on-line supplementary data for the present review.

The number of pooled studies was too little to allow the evaluation of publication bias and small-study-size effects by visual inspection of funnel plots.

\section{Effects of interventions}

A total of 928 patients were randomized to experimental $(n=466)$ or control interventions (placebo/active drug; $n=415$ ). Disclosed dropouts were 46 , (one patient missing). In one study, four patients in the placebo cohort withdrew from the trial during treatment, but it appears 
that data from these dropped-out patients were included in data analysis, though the trial report does not mention an intent-to-treat design (26).

In another study, 72 patients were randomized, but data from 32 patients per-cohort (64 in total) are presented; no information is given about the remaining 8 subjects (28). In the following paragraphs significant differences in outcome measures of interest for this review will be summarized. Study reports not allowing full evaluation of results due to incomplete efficacy data, or claiming interarm "significant difference" without showing statistical inference results (e.g. significance probability, or 95\% $\mathrm{CI}$ ), are not included in this section and are rated as having a high risk of reporting bias.

\section{Changes in stone size}

Ten studies included changes in stone size as primary or correlate endpoint $(13,19,20,22-28)$. The published reports of six of these studies didn't disclose intergroup statistical inference $(19,23,24,26-28)$.

In one study comparing Crataeva magna plus Musa paradisiaca vs. placebo, patients were divided in two groups, according to the stone size (group A, 5 to $10 \mathrm{~mm}$; group $\mathrm{B},>10 \mathrm{~mm}$ ) (20). In group $\mathrm{A}$, a $33.04 \%$ reduction in size was documented in the active arm, versus a 5.13\% increase in the placebo arm $(\mathrm{P}=0.017)$. In the largestone group B, no significant inter-arm differences in size reduction were found.

A study comparing Orthosiphon grandiflorus infusions with citrate evaluated the rate of stone size reduction per year (ROSRPY) at different time-points $(2,5,7,10,13$, 18 months). No significant differences were found between treatment arms at any study time-point (22).

In a study comparing Agropyrum repens extract plus potassium citrate, allopurinol, amiloride-hydrochlorothiazide and pyridoxine versus the same combination without the herbal extract, a significantly greater reduction of stone size in the former arm was claimed $(-3.6 \pm 0.9 \mathrm{~mm}$ vs $0.0 \pm 0.8 \mathrm{~mm}$; only $95 \% \mathrm{CI}$ provided) (13).

In a study by Singh et al., it was shown that Celosia argentea, a putative litholytic agent, can reduce stone size to a greater extent than citrate, after 6 months of therapy $(-2.57 \mathrm{~mm}$ versus $-1.82 \mathrm{~mm}$, respectively; $\mathrm{P}<0.05)(25)$.

\section{Changes in stone number}

Eight studies included changes in stone number as primary or correlate endpoint $(13,14,18,19,24,26-28)$. However, six studies didn't provide inference data describing intergroup statistical significance (14, 19, 24, 26-28). In a study by Brardi et al., comparing therapy with Agropyrum repens extract plus potassium citrate, allopurinol, amiloride-hydrochlorothiazide and pyridoxine versus the same combination without including the herbal agent, a significantly higher reduction in the total number of stones was claimed in favor of the former treatment arm $(-1.0 \pm 0.2$ vs $0.0 \pm 0.2$ stones; $95 \%$ confidence intervals available; probability not disclosed) (13).

In one open-label study comparing Phyllantus niruri with no treatment in post-lithotripsy patients, $90.6 \%$ of patients treated with the plant extract were free of lower caliceal stones (without residual fragments), compared to $70 \%$ of control patients (18). The difference was sta- tistically significant $(P=0.03)$. Treatment did not perform significantly better than no-treatment in patients affected by upper- or middle-caliceal calculi.

\section{Urinary excretion of calcium, urate, oxalate}

CALCIUM. Six studies included changes in urinary calcium excretion rates as primary or correlate endpoint $(13,17,19,23-25)$. Four study reports didn't disclose inference data about intergroup statistical significance $(19,23-25)$.

In the Brardi et al. study, no inter-arm differences in urinary calcium excretion rates were claimed (Agropyrum repens, $-52.8 \mathrm{mg} / 24 \mathrm{~h}$; controls, $+23.1 \mathrm{mg} / 24 \mathrm{~h}$; only $95 \%$ CI provided) (13).

A study by Lin et al. compared administration of "WuLing-san" (herbal components are listed in on-line Table 1) with placebo (17). After 1-month treatment, the 24hour urine calcium increased by $44.6 \%$ in the herbal formula arm, and by $62.7 \%$ in the placebo arm. The percentage of change in urinary calcium between the two groups was not significantly different $(P=0.62)$.

URATE. Six studies included changes in urinary urate excretion rates as primary or correlate endpoint $(13,17$, 19, 23-25), but four study reports didn't disclose inference data describing intergroup comparisons (19, 23-25).

In the Brardi et al. study no inter-arm differences in urinary urate excretion rates were claimed (Agropyrum repens, $-164.7 \mathrm{mg} / 24 \mathrm{~h}$; CIT -38 mg/24h) (13).

In the Lin et al. study ("Wu-Ling-san" versus placebo), the 24-hour urine uric acid increased by $27.6 \%$ in the herbal formula group and by $9.5 \%$ in the placebo group.

The inter-group difference was not significant $(\mathrm{P}=0.22)$ (17).

OXALATE. Five studies included changes in urinary oxalate concentrations as primary or correlate endpoint $(13,19,23-25)$. Four study reports out of five didn't disclose intergroup inference data $(19,23-25)$.

In the Brardi et al. study, no inter-arm differences in urinary oxalate excretion rates were claimed (Agropyrum repens, $-1.5 \mathrm{mg} / 24 \mathrm{~h}$; CIT +0.4 mg/24h) (13).

\section{Phytotherapy versus citrate (pooled analysis)}

We merged three studies, including in total 151 participants (75 in the phytotherapy arm, 76 in the control arm) $(23,24,25)$. All studies compared citrate as single agent with phytotherapy [Dolichus biflorus (23), Saxifraga ligulata, Crataeva nurvala and other components (24), Celosia argentea (25)]. Data obtained after 3 months of therapy were available for all three studies.

Pooled analysis resulted in a significantly higher decrease in mean stone size in the citrate group, compared to the phytotherapy group (mean inter-arm difference: 0.42 mm, 95\% CI: 0.23 to $0.60 ; Z=4.42, P<0.0001$ ) (Figure 2 , panel A). Heterogeneity of this comparison was minor $\left(\mathrm{I}^{2}=30 \%\right)$. The quality of the evidence, according to the GRADE guidelines (12), was rated as "low" (Table 1). Compared to herbal agents, citrate was significantly more effective in decreasing urinary excretion of urate after 3 months of therapy (mean inter-arm difference: $42.32 \mathrm{mg} / 24 \mathrm{~h}, 95 \% \mathrm{CI}: 19.44$ to $65.19 ; \mathrm{Z}=3.63, \mathrm{P}=$ 0.0003 ) (Figure 2). Pooled analysis showed no significant differences in the excretion rates of urinary calcium 


\section{Figure 2.}

Pooled analysis of changes in average stone size (panel A), and urinary calcium, urate and oxalate excretion rates (panel B) extracted from three randomized trials (23-25) comparing the effect of phytotherapy preparations with citrate after 3 months on-therapy. The number of randomized subjects, mean differences, the 95\% confidence intervals, the $Z$ value for the overall effect, the significance of the pooled comparisons and heterogeneity data $\left(\mathrm{Chi}^{2}, \mathrm{I}^{2}\right)$, are presented. Data to the right or left of the vertical line of forest plots represent a greater reduction in average stone size, or urinary excretion rates of stone components, in patients treated with citrate or phytotherapy, respectively. Diamonds represent pooled overall effect sizes for each outcome, which extend to the limits of the $95 \%$ confidence intervals of mean differences.

\begin{tabular}{|c|c|c|c|c|c|c|c|c|c|}
\hline \multirow{2}{*}{$\begin{array}{l}\text { Mean stone size } \\
\text { Study or Subgroup }\end{array}$} & \multicolumn{3}{|c|}{ Herbal medicine } & \multicolumn{3}{|c|}{ Citrate } & \multicolumn{2}{|r|}{ Mean Difference } & \multirow{2}{*}{$\begin{array}{c}\text { Mean Difference } \\
\text { IV, Random, } 95 \% \mathrm{Cl}\end{array}$} \\
\hline & Mean & SD & Total & Mean & SD & Total & Weight & IV, Random, $95 \% \mathrm{Cl}$ & \\
\hline Singh 2010 & -0.58 & 0.376 & 24 & -1.26 & 0.858 & 23 & $17.9 \%$ & $0.68[0.30,1.06]$ & \\
\hline Singh 2011 & -3.55 & 0.0866 & 30 & -3.93 & 0.088 & 30 & $73.3 \%$ & $0.38[0.34,0.42]$ & \\
\hline Singh 2012 & -1.09 & 1.09 & 21 & -1.26 & 0.858 & 23 & $8.8 \%$ & $0.17[-0.41,0.75]$ & \\
\hline Total $(95 \% \mathrm{Cl})$ & & & 75 & & & 76 & $100.0 \%$ & $0.42[0.23,0.60]$ & \\
\hline \multicolumn{9}{|c|}{$\begin{array}{l}\text { Heterogeneity: } \text { Tau }^{2}=0.01 ; \mathrm{Chi}^{2}=2.86, \mathrm{df}=2(\mathrm{P}=0.24) ; \mathrm{I}^{2}=30 \% \\
\text { Test for overall effect: } \mathrm{Z}=4.42(\mathrm{P}<0.0001)\end{array}$} & $\begin{array}{ccccc}-1 & -0.5 & 0 & 0.5 & 1 \\
\text { Favours herbal medicine } & \text { Favours citrate }\end{array}$ \\
\hline
\end{tabular}

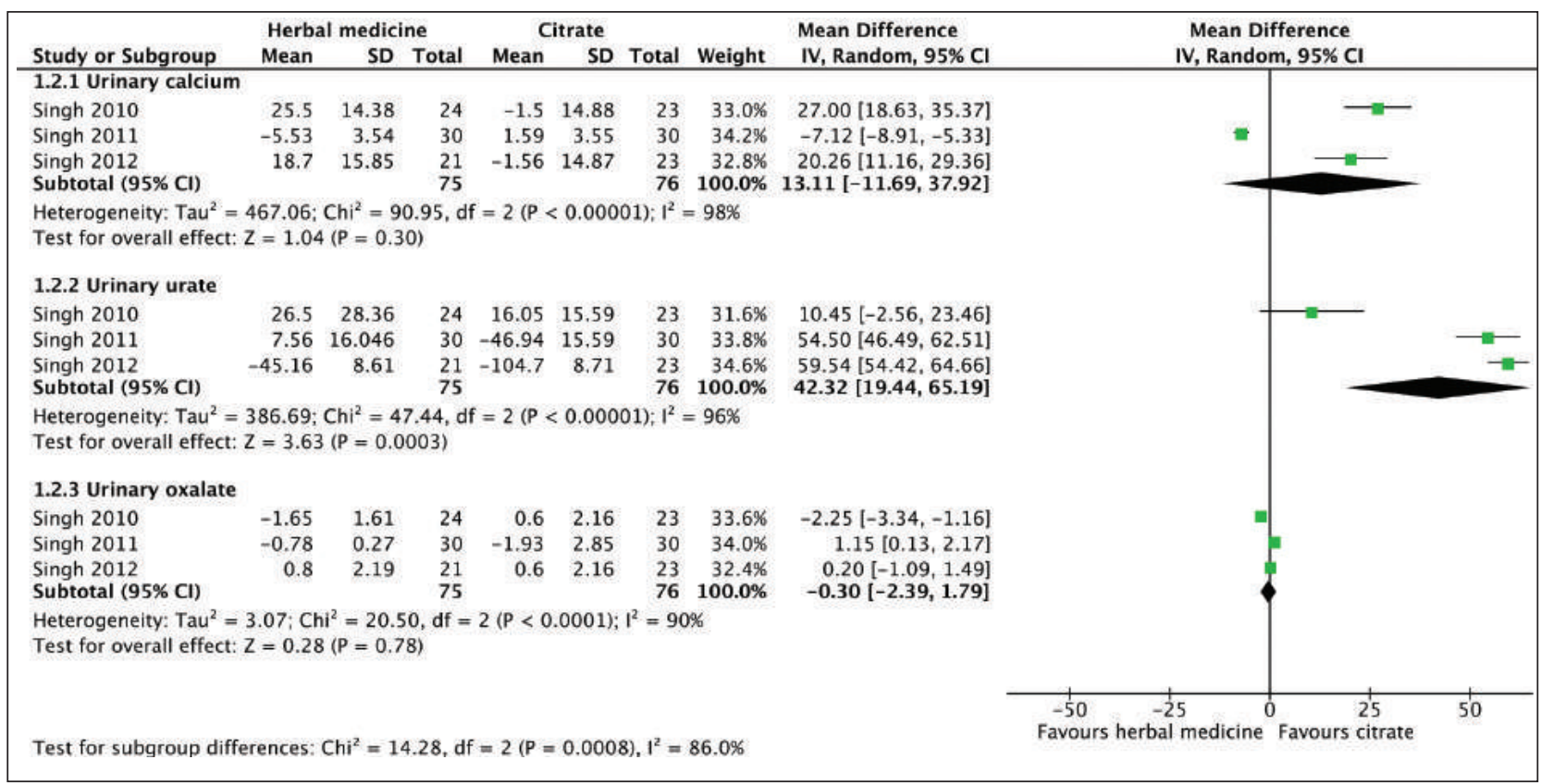

or oxalate at the same time point (Figure 2, panel B). All comparisons of excretion rates of urinary risk factors for stone formation were characterized by considerable heterogeneity (calcium, $\mathrm{I}^{2}=98 \%$; urate, $\mathrm{I}^{2}=96 \%$; oxalate, $\mathrm{I}^{2}=90 \%$, Figure 2 ), and the quality of the evidence, according to the GRADE guidelines, was rated as "very low" in all cases (Table 1).

In summary, meta-analysis suggests that, compared to the herbal remedies listed above, citrate can be more effective in decreasing both the size of urinary tract stones and the urinary excretion rate of urate.

It is known that the most important risk factor for urate stone formation is persistently acidic urine, and that alkalization of urine with potassium citrate or bicarbonate is active in decreasing urinary saturation with respect to uric acid. This is an effective strategy for dissolution of existing stones and for prevention of recurrence (29-31). Citrate is also known to decrease urinary excretion of calcium, but not of oxalate (32). In this respect, visual inspection of forest plots (Figure 2, panel B) suggests the absence of a frank effect of citrate or herbal medicines on urinary oxalate excretion, but points to heterogeneity generated by the Singh 2011 study (24) as the factor preventing pooled analysis from confirming significant superiority of citrate in decreasing urinary levels of calcium (sensitivity test without Singh 2011: mean difference $=23.88 \mathrm{mg} / 24 \mathrm{~h}, 95 \% \mathrm{CI}: 17.29$ to $30.46 ; \mathrm{Z}=7.10, \mathrm{P}<$ $\left.0.00001 ; \mathrm{I}^{2}=12 \%\right)$. In this respect, it is helpful to remark that the Singh 2010 (23) and Singh 2012 (25) studies were performed by the same research group, and that the first author of Singh 2011 (24) is a coincidental namesake. Due to the very small number of pooled studies, sensitivity test results must be interpreted with a high degree of caution.

\section{Phytotherapy versus placebo (pooled analysis)}

Two studies compared a herbal agent [Wu-Ling-San formula, whose components are listed in on-line Table 1 (17); Phillantus niruri (19)] with placebo. The only comparable and poolable endpoints were the variations of 
Figure 3.

Pooled analysis of mean changes in the excretion rates of urinary calcium and urate extracted from two randomized trials $(17,19)$ comparing the effect of phytotherapy preparations with placebo. The number of randomized subjects, mean differences, the 95\% confidence intervals, the $Z$ value for the overall effect, the significance of the pooled comparison and heterogeneity data $\left(\mathrm{Chi}^{2}, \mathrm{I}^{2}\right)$, are presented. Data to the right or left of the vertical line of forest plots represent a greater reduction in urinary excretion rates of calcium or urate in patients treated with placebo or phytotherapy, respectively. Diamonds represent pooled overall effect sizes for each outcome, which extend to the limits of the 95\% confidence intervals of mean differences.

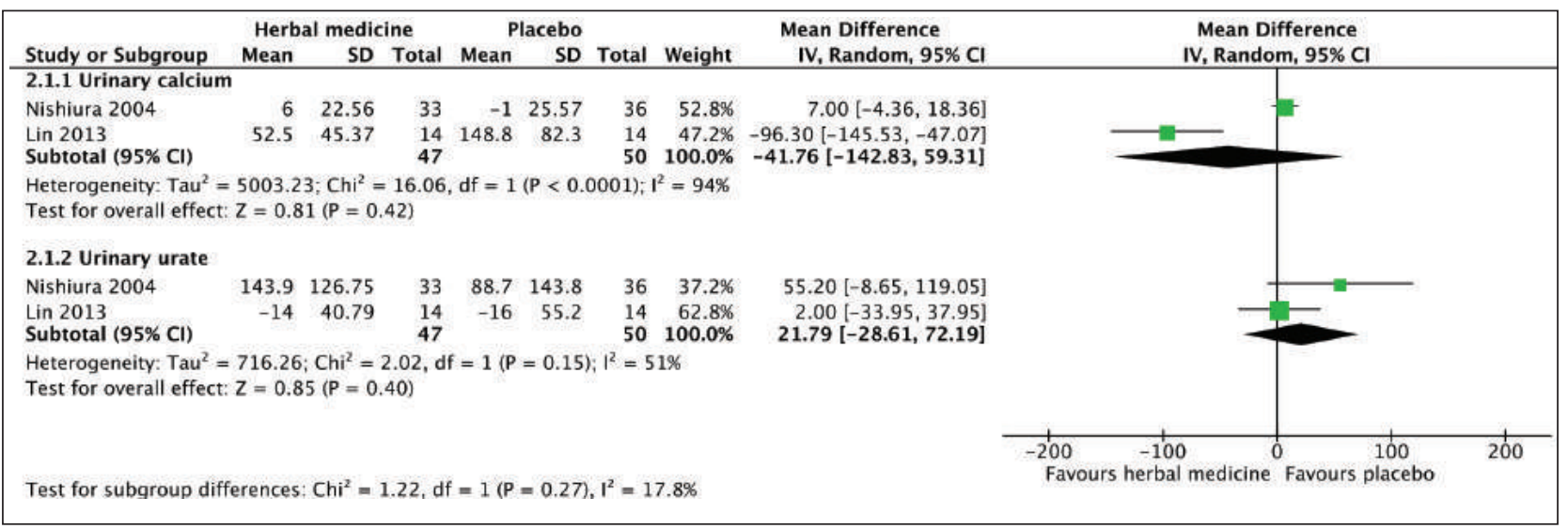

Figure 4.

Pooled analysis of changes in average stone size extracted from two randomized trials $(26,27)$ comparing the effect of a preparation containing Didymocarpus pedicellata (DP) combined with other herbal agents ("Cystone"; a list of components is featured in on-line Table 1) with placebo after 3 months on-therapy. The number of randomized subjects, mean differences, the $95 \%$ confidence intervals, the $Z$ value for the overall effect, the significance of the pooled comparisons and heterogeneity data $\left(\mathrm{Chi}^{2}, \mathrm{I}^{2}\right)$, are presented. Data to the left or right of the vertical line of forest plots represent a greater reduction in average stone size in patients treated with the DP preparation or placebo, respectively. Diamonds represent pooled overall effect sizes for each outcome, which extend to the limits of the 95\% confidence intervals of mean differences.

\begin{tabular}{|c|c|c|c|c|c|c|c|c|c|}
\hline $\begin{array}{l}\text { Mean stone size } \\
\text { Study or Subgroup }\end{array}$ & \multicolumn{3}{|c|}{ "Cystone" } & \multicolumn{3}{|c|}{ Placebo } & \multirow{2}{*}{$\begin{array}{r}\text { Weight } \\
49.7 \%\end{array}$} & \multirow{2}{*}{$\begin{array}{l}\text { Mean Difference } \\
\text { IV, Random, 95\% Cl } \\
-7.11[-7.88,-6.34]\end{array}$} & $\begin{array}{l}\text { Mean Difference } \\
\text { IV, Random, } 95 \% \mathrm{CI}\end{array}$ \\
\hline Mohanty 2010 & -6.05 & 1.39 & 26 & 1.06 & 1.44 & 26 & & & $-1-$ \\
\hline Shekar Kumaran 2011 & -2.7 & 0.63 & 30 & 0.07 & 0.91 & 30 & $50.3 \%$ & $-2.77[-3.17,-2.37]$ & 날 \\
\hline Total $(95 \% \mathrm{Cl})$ & & & 56 & & & 56 & $100.0 \%$ & $-4.93[-9.18,-0.67]$ & \\
\hline \multicolumn{9}{|c|}{$\begin{array}{l}\text { Heterogeneity: } \mathrm{Tau}^{2}=9.32 ; \mathrm{Chi}^{2}=96.64, \mathrm{df}=1(\mathrm{P}<0.00001) ; \mathrm{I}^{2}=99 \% \\
\text { Test for overall effect: } \mathrm{Z}=2.27(\mathrm{P}=0.02)\end{array}$} & $\begin{array}{cccccc}-4 & 1 & 1 & 1 & 1 \\
\text { Favours "Cystone" } & 2 & 4 \\
\text { Favours placebo }\end{array}$ \\
\hline
\end{tabular}

calcium and urate urinary excretion rates. Analysis revealed no significant differences between treatment arms in either endpoint comparison (Figure 3).

Heterogeneity was "considerable" for the calcium endpoint (94\%), and "substantial" for the urate endpoint (51\%), according to the Cochrane Handbook heterogeneity interpretation guide (33). The quality of the evidence was rated as "very low" for this comparison.

Two studies performed by the Pralhad Patki research group compared the effect of a herbal preparation containing Didymocarpus pedicellata (DP) combined with other herbal agents (a complete list of components is provided in on-line Table 1) with placebo $(26,27)$. Pooled analysis showed that the DP preparation was superior than placebo in inducing size reduction (mean difference: DP preparation, 4.93 mm lower; $95 \%$ CI: -9.18 to -0.67 ; $\mathrm{Z}=2.27, \mathrm{P}=0.02$, Figure 4 ) and total clearance (risk ratio: $6.19,95 \% \mathrm{CI}: 2.60$ to $14.74 ; \mathrm{Z}=4.12, \mathrm{P}<0.0001$, Figure 5) of renal and ureteral stones after 3 months of therapy. Heterogeneity was "considerable" for the stone size endpoint (99\%) and null for the stone clearance endpoint $(0 \%)$. The quality of the evidence was rated as "moderate" for this comparison.

\section{Adverse effects of treatments}

Three study reports lacked a section listing adverse effects (AE) of treatment (19, 23, 25). Eight studies reported no $\mathrm{AE}$ or side effect, nor any complaint from treated patients (13-18, 27, 28).

The Patankar et al. study report mentions "nausea, giddiness, epigastric pain" assessed in "comparable" fractions of patients in both treatment arms (Crataeva magna plus Musa paradisiaca vs. placebo; data not disclosed) (20).

The Premgamone 2001 et al. study (22), comparing the effect of Orthosiphon grandiflorus infusions with citrate, reports fatigue and loss of appetite in $26 \%$ patients belonging to the citrate arm, and no complaints in the arm treated with the herbal agent (no statistics available). In the Singh 2011 study, citrate induced upper GI disturbances in 4 subjects (13.3\%), whereas no AE were 
Figure 5.

Pooled analysis of mean changes in stone clearance extracted from two randomized trials $(26,27)$ comparing the effect of a preparation containing Didymocarpus pedicellata (DP) combined with other herbal agents ("Cystone"; a list of components is featured in on-line Table 1) with placebo after 3 months on-therapy. The number of randomized subjects, risk ratios for stone clearance, the 95\% confidence intervals for risk ratios, the $Z$ value for the overall effect, the significance of the pooled comparison and heterogeneity data $\left(\mathrm{Chi}^{2}, \mathrm{I}^{2}\right)$, are presented. Data to the right or left of the vertical line of forest plots represent a higher risk for stone clearance in patients treated with the DP preparation or placebo, respectively. Diamonds represent the pooled overall effect sizes for each outcome, which extend to the limits of the $95 \%$ confidence intervals of risk ratios.

\begin{tabular}{|c|c|c|c|c|c|c|c|c|c|c|}
\hline $\begin{array}{l}\text { Stone clearance } \\
\text { Study or Subgroup }\end{array}$ & \multicolumn{2}{|c|}{ "Cystone" } & \multicolumn{2}{|c|}{ Placebo } & Weight & $\begin{array}{c}\text { Risk Ratio } \\
\text { M-H, Random, 95\% Cl }\end{array}$ & \multicolumn{4}{|c|}{$\begin{array}{c}\text { Risk Ratio } \\
\text { M-H, Random, } 95 \% \mathrm{Cl}\end{array}$} \\
\hline Mohanty 2010 & 13 & 26 & 2 & 26 & $39.2 \%$ & $6.50[1.63,25.99]$ & & & & \\
\hline Shekar Kumaran 2011 & 18 & 30 & 3 & 30 & $60.8 \%$ & $6.00[1.97,18.25]$ & & & & \\
\hline Total $(95 \% \mathrm{Cl})$ & & 56 & & 56 & $100.0 \%$ & $6.19[2.60,14.74]$ & & & & \\
\hline \multirow{2}{*}{\multicolumn{7}{|c|}{$\begin{array}{l}\text { Total events } \\
\text { Heterogeneity: } \text { Tau }^{2}=0.00 ; \mathrm{Chi}^{2}=0.01, \mathrm{df}=1(\mathrm{P}=0.93) ; \mathrm{I}^{2}=0 \% \\
\text { Test for overall effect: } \mathrm{Z}=4.12(\mathrm{P}<0.0001)\end{array}$}} & & & & \\
\hline & & & & & & & 0.01 & 0.1 Favours placebo & $\begin{array}{c}10 \\
\text { Favours "Cystone" }\end{array}$ & 100 \\
\hline
\end{tabular}

recorded in the patient cohort treated with a Saxifraga ligulata plus Crataeva nurvala extract (full list of components available in on-line Table 1) (24).

In the Premgamone 2009 study, comparing the effect of Orthosiphon grandiflorus (OG) extract versus placebo, a significant difference in the number of patients reporting adverse effects was found after 14 days on-therapy (treatment arm: $2.8 \%$ patients with AE; placebo arm: $17.5 \%$ patients with $\mathrm{AE} ; \mathrm{P}=0.03$ ) (21). Adverse effects were myofascial pain (OG, $n=1$; placebo, $n=4)$, fatigue $(O G$, $\mathrm{n}=0$; placebo, $\mathrm{n}=2$ ), back pain ( $\mathrm{OG}, \mathrm{n}=1$; placebo, $\mathrm{n}$ $=2$ ), gastrointestinal symptoms ( $O G, n=0$; placebo, $n=$ 3), "other" $A E(O G, n=0)$; placebo, $n=3)$ (subgroup statistics not available). In the Shekar Kumaran and Patki trial, vomiting, gastric irritation, and dyspepsia were recorded in three different patients belonging to the group treated with the DP preparation. The authors report "solitary incidence of gastric irritation" in the placebo group, without disclosing additional details (26).

\section{Conclusions}

Studies on the effect of herbal products on the formation and growth of urinary stones are numerous but generally of low quality.

Meta-analytical evidence of moderate quality has shown that a herbal formulation containing Didymocarpus pedicellata (DP) combined with other herbal agents was superior to placebo in inducing size reduction and total clearance of renal and ureteral stones, whereas pooled analysis of three studies with low quality of evidence resulted that citrate treatment was able to decrease the mean stone size of stones at an higher extent compared to phytotherapy.

A limitation of most studies was the absence of information on the composition of the stones.

Furthermore, imaging is more often based on ultrasound that does not allow to distinguish between radiopaque and radiolucent stones. The lack of information on stone composition makes it difficult to fully evaluate the effects of treatment on stone dissolution. Indeed, while uric acid stones can be easily dissolved by administration of alkali salts raising the urinary $\mathrm{pH}$ to less acid values of the physiological range, the dissolution of calcium stones is more difficult. Calcium phosphate stones can be dissolved by irrigation of kidney cavities with solutions with a high concentration of citrate or other inhibitors activity of the crystallization of calcium salts, as the solution of Suby or hemiacidrin (Renacidin). The concentrations of citrates used in these solutions are, however, higher than those that can be achieved after oral administration of citrate. In fact the solutions of Suby are obtained by dissolving more than 30 grams of citric acid monohydrate in a liter of aqueous solvent with $\mathrm{pH}$ around 4. Moreover these solutions are not capable of dissolving calcium oxalate stones which require the addition of calcium chelants, such as EDTA, that can cause local and systemic toxicity (34).

For this reason, dissolution of calcium stones by oral treatment is debatable, although some studies have demonstrated the efficacy of citrate therapy in facilitating the clearance and in preventing the regrowth of residual fragments after lithotripsy (35-39).

The published comparisons of excretion rates of urinary risk factors for stone formation are characterized by considerable heterogeneity and very low quality of evidence. No significant variations of calcium and urate urinary excretion rates between treatment with herbal agents and placebo was observed. Pooled analysis demonstrated that citrate was significantly more effective in decreasing urinary excretion of urate compared to herbal agents although no significant differences of the two treatments in the excretion rates of urinary calcium or oxalate were observed. However, the measurement of uric acid in the urine is influenced by the urinary $\mathrm{pH}$; hence, the higher levels of uric acid measured in the urine after treatment with citrates could be an analytic effect due to higher urinary $\mathrm{pH}$ levels.

The effect of herbal products could be unrelated to modifications of the metabolism of urinary risk factors. In fact, herbal products may contain macromolecules with direct inhibitory effects on crystallization or enzymes able to digest the organic matrix of the stone. A limitation of herbal medicine is our inability to recognize what is the 
active component among the several molecules present in every plant. Each substance could have effects on the metabolism with consequent modification of the excretion of the urinary risk factors but also an antioxidant action with protective effect on the renal parenchyma or a direct effect on the crystalline structure of the stone.

Finally, additional factor of uncertainty are the seasonal geographical variability, as well as the methods for cultivating, extracting and analyzing the bioactive components of these plants.

Herbal medicine is an attractive alternative to the use of synthetic drugs that are often viewed with suspicion by patients due to the risk of side effects. The regulatory rules for production of these preparations rigid than for synthetic products and their marketing is less complicated and less expensive. However, the results of this metaanalysis make available to healthcare providers a limited amount of evidence about the possible use of herbal products to dissolve or eliminate urinary stones.

On the other hand, these products did not show any effect on the metabolism of the major urinary risk factors. Potential users of these products should be informed about the lack of conclusive evidence on the effectiveness of herbal products for stone treatment and policy makers should seek additional information before introducing reimbursement policies for these products. The results of the meta-analysis do not allow robust conclusions on the role of herbal medicine in the treatment of urinary stones because only a limited number of herbal products were considered. Additional, adequately powered and designed randomized controlled trials are warranted to strengthen the available evidence and to evaluate the effect of other herbal products.

\section{Tables and Search strategy are posted as Supplemen- tary material on www.aiua.it}

\section{References}

1. Romero V, Akpinar H, Assimos DG. Kidney stones: a global picture of prevalence, incidence, and associated risk factors. Rev Urol. 2010; 12:e86-96.

2. Pearle MS, Calhoun EA, Curhan GC. Urologic Diseases of America Project. Urologic diseases in America project: urolithiasis. J Urol. 2005; 173:848-57.

3. Boyce CJ, Pickhardt PJ, Lawrence EM, et al. Prevalence of urolithiasis in asymptomatic adults: objective determination using low dose noncontrast computerized tomography. J Urol. 2010; 183:1017-21.

4. Prezioso D, Illiano E, Piccinocchi G, et al. Urolithiasis in Italy: an epidemiological study. Arch Ital Urol Androl. 2014; 86:99-102.

5. Moe OW. Kidney stones: pathophysiology and medical management. Lancet. 2006; 367:333-44.

6. Sirohi M, Katz BF, Moreira DM, Dinlenc C. Monthly variations in urolithiasis presentations and their association with meteorologic factors in New York City. J Endourol. 2014; 28:599-604.

7. Türk C, Petrík A, Sarica K, et al. EAU Guidelines on Interventional Treatment for Urolithiasis. Eur Urol. 2015 Sep 3. pii: S0302-2838(15) 00700-9. doi: 10.1016/j.eururo.2015.07.041 [Epub ahead of print]

8. Kijvikai $\mathrm{K}$, de la Rosette JJ. Assessment of stone composition in the management of urinary stones. Nat Rev Urol. 2011; 8:81-5.
9. Türk C, Petrík A, Sarica K, et al. EAU Guidelines on Diagnosis and Conservative Management of Urolithiasis. Eur Urol. 2015 Aug 26. pii: S0302-2838(15)00699-5. doi: 10.1016/j.eururo.2015. 07.040 [Epub ahead of print]

10. http://www.prisma-statement.org/Default.aspx

11. Higgins JP, Altman DG, Gøtzsche PC, et al. The Cochrane Collaboration's tool for assessing risk of bias in randomised trials. BMJ. 2011; 343:d5928.

12. Guyatt GH, Oxman AD, Kunz R, et al. What is "quality of evidence" and why is it important to clinicians? BMJ. 2008; 336: 995-8.

13. Brardi S, Imperiali P, Cevenini $G$, et al. Effects of the association of potassium citrate and agropyrum repens in renal stone treatment: results of a prospective randomized comparison with potassium citrate. Arch Ital Urol Androl. 2012; 84:61-7.

14. Ceban A. Efficacy of a fixed combination of Centaurii herba, Levistici radix and Rosmarini folium in urinary lithiasis. Results of an open randomised cohort study. Z Phytother. 2012; 33:19-23.

15. Erickson SB, Vrtiska TJ, Lieske JC. Effect of Cystone ${ }^{\circledR}$ on urinary composition and stone formation over a one year period. Phytomedicine. 2011; 18:863-7.

16. Erickson SB, Vrtiska TJ, Canzanello VJ, Lieske JC. Cystone ${ }^{\circledR}$ for 1 year did not change urine chemistry or decrease stone burden in cystine stone formers. Urol Res. 2011; 39:197-203.

17. Lin E, Ho L, Lin MS, et al. Wu-Ling-San formula prophylaxis against recurrent calcium oxalate nephrolithiasis - a prospective randomized controlled trial. Afr J Tradit Complement Altern Med. 2013; 10:199-209.

18. Micali S, Sighinolfi MC, Celia A, et al. Can Phyllanthus niruri affect the efficacy of extracorporeal shock wave lithotripsy for renal stones? A randomized, prospective, long-term study. J Urol. 2006; 176:1020-2.

19. Nishiura JL, Campos AH, Boim MA, et al. Phyllanthus niruri normalizes elevated urinary calcium levels in calcium stone forming (CSF) patients. Urol Res. 2004; 32:362-6.

20. Patankar S, Dobhada S, Bhansali M, et al. A prospective, randomized, controlled study to evaluate the efficacy and tolerability of Ayurvedic formulation "varuna and banana stem" in the management of urinary stones. J Altern Complement Med. 2008; 14:1287-90.

21. Premgamone A, Sriboonlue P, Maskasem S, et al. Orthosiphon versus placebo in nephrolithiasis with multiple chronic complaints: a randomized control trial. Evid Based Complement Alternat Med. 2009; 6:495-501.

22. Premgamone A, Sriboonlue $P$, Disatapornjaroen $W$, et al. A long-term study on the efficacy of a herbal plant, Orthosiphon grandiflorus, and sodium potassium citrate in renal calculi treatment. Southeast Asian J Trop Med Public Health. 2001; 32:654-60.

23. Singh RG, Behura SK, Kumar R. Litholytic property of Kulattha (Dolichous biflorus) vs potassium citrate in renal calculus disease: a comparative study. J Assoc Physicians India. 2010; 58:286-9.

24. Singh I, Bishnoi I, Agarwal V, Bhatt S. Prospective randomized clinical trial comparing phytotherapy with potassium citrate in management of minimal burden ( $\leq 8 \mathrm{~mm})$ nephrolithiasis. Urol Ann. 2011; 3:75-81.

25. Singh RG, Singh TB, Kumar R, et al. A comparative pilot study of litholytic properties of Celosia argental (Sitivaraka) versus potassium citrate in renal calculus disease. J Altern Complement Med. 2012; $18: 427-8$ 
26. Shekar Kumaran MG, Patki PS. Evaluation of an Ayurvedic formulation (Cystone), in urolithiasis: A double blind, placebo-controlled study. Eur J Integr Med. 2011; 3:23-28.

27. Mohanty NK, Nayak RL, Patki PS. Safety and Efficacy of an Ayurvedic Formulation Cystone in Management of Ureteric Calculi: A Prospective Randomized Placebo Controlled Study. Am J Pharmacol Toxicol. 2010; 5:58-64.

28. Upadhyay V, Malekar S, Deshpande S, Ahmad S, Shamsuddin. Safety and efficacy of UNEX capsules in management of ureteric calculi: A prospective, randomised placebo-controlled study. Int J Green Pharm. 2011; 5:346-9.

29. Shekarriz B, Stoller ML. Uric acid nephrolithiasis: current concepts and controversies. J Urol. 2002; 168:1307-14.

30. Pak CY, Sakhaee K, Fuller C. Successful management of uric acid nephrolithiasis with potassium citrate. Kidney Int. 1986; 30:422-8.

31. Cicerello E, Merlo F, Maccatrozzo L. Urinary alkalization for the treatment of uric acid nephrolithiasis. Arch Ital Urol Androl. 2010; 82:145-8.

32. Song Y, Hernandez N, Shoag J, et al. Potassium citrate decreases urine calcium excretion in patients with hypocitraturic calcium oxalate nephrolithiasis. Urolithiasis. 2015 Nov 18. [Epub ahead of print] PubMed PMID: 26582172
33. Higgins JPT, Green S. Cochrane Handbook for Systematic Reviews of Interventions. Chichester, England: John Wiley \& Sons Ltd; 2009.

34. Oosterlinck W, Verbeeck R. Chemolysis of calcium containing calculi. A review. Acta Urol Belg. 1994; 62:31-7.

35. Fine JK, Pak CYC, Preminger GM. Effect of medical management and residual fragments on recurrent stone formation following shock wave lithotripsy. J Urol. 1995; 153: 27-33.

36. Cicerello E, Merlo F, Gambaro G, et al. Effect of alkaline citrate therapy on clearance of residual renal stone fragments after extracorporeal shock wave lithotripsy in sterile calcium and infection nephrolithiasis. J Urol. 1994; 151:5-9.

37. Soygur T, Akbay A, Kupely S. Effect of potassium citrate therapy on stone recurrence and residual fragments after shock wave lithotripsy in lower calyceal calcium oxalatae urolithiasis: a randomized controlled trial J Endourol. 2002; 16:149-152.

38. Sarica K, Erturhan S, Yurtenseven C, et al. Effect of potassium citrate therapy on stone recurrence and regrowth after shock wave lithotripsy in children J Endourol. 2006; 20:875-879.

39. Lojanapiwat BM, Tanthanuch MC, Pripathanont C, et al. Alkaline citrate reduces stone recurrence and regrowth after shock wave lithotripsy and percutaneous nephrolithotomy. Int Braz J Urol. 2011; 37:611-616.

\section{Correspondence}

Elena Monti, Dr Sci

elena.monti@uninsubria.it

Department of Biotechnology and Life Sciences,

Università degli Studi dell'Insubria, Busto Arsizio, Italy

Alberto Trinchieri, $M D$

a.trinchieri@ospedale.lecco.it

Urology Unit, A. Manzoni Hospital, Lecco, Italy

Vittorio Magri, MD

vittorio.magri@virgilio.it

Urology Secondary Care Clinic, ASST-Nord,

Milano, Italy

Anne Cleves

lynchAE1@cardiff.ac.uk

Cancer Research Wales Library, Cardiff University Velindre Hospital, Cardiff, UK

Gianpaolo Perletti, Dr. Sci, M Clin Pharmacol (Corresponding Author) gianpaolo.perletti@uninsubria.it

Dept. of Biotechnology and Life Sciences, Università degli Studi dell'Insubria Via A. da Giussano, 10 - 21052 Busto Arsizio, Italy 